\title{
LC-Multistage Mass Spectrometry for the Characterization of Poly(Butylene Adipate-co-Butylene Terephthalate) Copolyester
}

\author{
Junkan Song, ${ }^{1}$ Alena Šišková, ${ }^{2}$ Marcel G. Simons, ${ }^{1}$ Wiltod J. Kowalski, ${ }^{2}$ \\ Marek M. Kowalczuk, ${ }^{3}$ Oscar F. van den Brink ${ }^{1}$ \\ ${ }^{1}$ AkzoNobel, Research Development and Innovation, P.O. Box 10, Deventer, 7400AA, The Netherlands \\ ${ }^{2}$ Jan Długosz University in Czestochowa, Institute of Chemistry and Environmental Protection, Częstochowa, Poland \\ ${ }^{3}$ Polish Academy of Sciences, Centre of Polymer and Carbon Materials, Zabrze, Poland
}

\begin{abstract}
A comprehensive study using liquid chromatography electrospray ionization multistage mass spectrometry (LC-ESI $\mathrm{MS}^{n}$ ) was performed to get detailed structural information on poly(butylene adipate-co-butylene terephthalate) co-polyester and its product of partial degradation. LC-MS and LC-MS ${ }^{n}$ identified the existence of cyclic structures in the original samples that disappear completely during the degradation. The occurrence of methanol transesterification in the degradation process was confirmed. $\mathrm{MS}^{2}$ on the first ${ }^{13} \mathrm{C}$ isotope peak helped to determine the elemental composition of the fragments and facilitated end group determination. The method can be used to provide an alternative for high mass accuracy $\mathrm{MS}^{2}$ experiments. Sequence information was also revealed for certain copolymeric structures.
\end{abstract}

Keywords: Aliphatic-aromatic copolyester, End groups, Multistage mass spectrometry, Liquid chromatography

\section{Introduction}

$\mathrm{T}$

raditional plastic materials such as polyethylene, polypropylene, or polystyrene are very resistant to environmental influences. The growing public and scientific concern on plastic waste in the last two decades have stimulated the development of many controlled biologically degradable polymers.

Electronic supplementary material The online version of this article (doi:10.1007/s13361-010-0071-y) contains supplementary material, which is available to authorized users.

Correspondence to: Oscar F. van den Brink; e-mail: oscar.vandenbrink@ akzonobel.com
Polyesters, one specific class of the biodegradable polymers, play an important role due to their intensive industrial utilization. They are broadly applied in specialty fibers, plastics, packaging, films and engineering materials.

Within the class of polyesters, aliphatic polyesters are considered important biodegradable polymers [1]. The properties of commercialized biodegradable polymeric materials, such as melting point or mechanical properties, are usually rather poor and below the requirements for many applications. In order to improve the material characteristics, aromatic monomers are introduced into the polyester structure. Aromatic polyesters possess outstanding mechanical and processing properties. They are, however, not biodegradable. The biodegradability of aliphatic-aromatic co-polyesters decreases with the increase of the aromatic part in the chain [2-6]. 
Ecoflex is the trade name for thermoplastic co-polyester produced by BASF and represents an interesting group of biodegradable co-polyesters. The co-polyester (abbreviated as BTA) is composed of terephthalic acid (T), adipic acid (A), and 1, 4-butanediol (B) monomers. The biodegradability has been intensively evaluated by many authors [2-4, $7,8]$. The thermal properties of the polymer composition have been studied by means of DSC [5], and the general structures and composition information have been investigated by using NMR and GC-MS [8-10]. Many researchers [6, 11-13] have also demonstrated that the copolyester structure (random or block) can be investigated using multistage mass spectrometry $\left(\mathrm{MS}^{n}\right)$ with various soft ionization techniques.

The combination of liquid chromatography with mass spectrometry (LC-MS) is often applied to polymer characterization in order to avoid effects such as ion suppression that lead to mass discrimination in the detection of higher-mass portions of the material. The online connection of gradient polymer elution chromatography (GPEC) $[14,15]$ to MS separates the polymer distribution based on the differences in solubility among the polymer molecules with different chemical compositions.

In this work, we used LC-MS ${ }^{n}$ to study the structure of BTA oligomers and its partial degradation under alkaline conditions. A comprehensive study using LC-ESI MS ${ }^{n}$ was performed to get detailed structural information on both the original BTA and its partially degraded products. Although the original BTA has a relatively large molecular weight, studying its low molecular weight oligomers will provide important information on the general structure. On the other hand, the degradation products that mostly have low molecular weights fit in the detection range of multistage mass spectrometry. Hence, the majority of the degradation products could be studied using LC-MS ${ }^{n}$.

\section{Experimental}

\section{Sample Degradation}

Poly[(tetramethylene terephthalate)-co-(tetramethylene adipate)], BTA, was kindly supplied by BASF Ludwigshafen, Germany. The BTA partial degradation was carried out under alkaline conditions, in a similar way to the method described by Adamus et al. [6]. The starting BTA sample (BTA-O), in the form of granulate, was dissolved in chloroform $\left(\mathrm{CHCl}_{3}\right)(\mathrm{POCH}$, Gliwice, Poland). Degradation was performed in the mixture $(1: 5 \mathrm{vol} / \mathrm{vol})$ of $1.5 \mathrm{~mol} . \mathrm{L}^{-1}$ aqueous solution of tetrabutylammonium hydroxide (TBA $\mathrm{OH})$ (Sigma-Aldrich Chemie GmbH, Steinheim, Germany) and methanol (POCH). The procedure was performed at $35^{\circ} \mathrm{C}$ (BTA-35) or $75^{\circ} \mathrm{C}$ (BTA-75).

\section{Liquid Chromatography-Mass Spectrometry}

Samples with a concentration of $3 \mathrm{mg} \cdot \mathrm{mL}^{-1}$ in THF were prepared. The LC system used for separation was Agilent 1100 series LC binary pump with diode array detector
(DAD). The LC column in the LC-ESI-MS setup was an Alltech Kromasil C18 $(150 \mathrm{~mm} \times 4.6 \mathrm{~mm})$. During analysis, the column was maintained at $30{ }^{\circ} \mathrm{C}$. A gradient of $10 \%$ tetrahydrofuran (THF) (Sigma-Aldrich)/90\% $\mathrm{H}_{2} \mathrm{O}$ (from Millipore Direct-Q) to $100 \%$ tetrahydrofuran (THF) was used as mobile phase. $0.1 \%$ formic acid (FA) (Fluka) was added to both mobile phases. The running time of the gradient was $40 \mathrm{~min}$. In most of the cases, sodium iodide (NaI) was added post-column using a Cole-Parmer 74900 series syringe pump at $0.6 \mathrm{~mL} / \mathrm{h}$. It was dissolved in THF (Sigma-Aldrich) at an approximate concentration of $1 \mu \mathrm{g}$. $\mathrm{mL}^{-1}$. The mass spectrometer used in this study was a Bruker Esquire 3000plus. The nebulizer pressure of this instrument was set to $60.0 \mathrm{psi}$, the drying gas flow to $11.0 \mathrm{~L}$. $\mathrm{min}^{-1}$, and the drying gas temperature to $360{ }^{\circ} \mathrm{C}$. The maximum accumulation time was $50.0 \mathrm{~ms}$. Data were processed and analyzed using Bruker DataAnalysis 3.3.

\section{Results and Discussion}

As a first level of observation of the effect of degradation on the BTA, GPC was applied to investigate the changes in the molecular weight distribution. Detailed GPC results are presented in the Supplementary Material. The data showed that the reaction is more progressed under conditions of higher temperature $\left(75^{\circ} \mathrm{C}\right)$ although the structures of the degraded products are similar at both temperatures $\left(35^{\circ} \mathrm{C}\right.$ and $75{ }^{\circ} \mathrm{C}$ ). The number-average molecular weight before and after degradation were 16,000 and below 400 , respectively. The weight-average molecular weights were 38,000 before degradation and below 3000 after degradation. The detection range of the MS only covers part of the molecular weight distribution of the oligomers for BTA-O, although the oligomer structures are still representative of the polymer. The mass range of the degraded samples, on the other hand, can be fully covered by MS. Complementary ${ }^{1} \mathrm{H}$, ${ }^{13} \mathrm{C}$, DEPT, and HMBC NMR results are presented in the Supplementary Material.

Figure 1a shows LC-MS data as log abundance of $[\mathrm{M}-\mathrm{H}]$ (data point weight) versus $m / z$ (as y-axis) versus chromatographic elution time (as $\mathrm{x}$-axis). Figure $1 \mathrm{~b}$ shows the abundance of the BTA molecules with positive adduct ions versus $m / z$ (as y-axis) versus chromatographic elution time (as $\mathrm{x}$-axis). Summation of the data shown in Figure 1 over the elution time from 15 to 32 min resulted in the mass spectra shown in Figure 2a and $b$.

The $m / z$ difference between the peaks in Figure $1 \mathrm{a}$ and $\mathrm{b}$ is 24, which can be observed by comparison of the corresponding expanded spectra $(\mathrm{m} / \mathrm{z} 800-1100)$ Figure 2c and d, e.g., $\mathrm{I}_{1}$ in $2 \mathrm{c}(\mathrm{m} / \mathrm{z} 945.7)$ and $2 \mathrm{~d}(\mathrm{~m} / \mathrm{z}$ 969.5). The cause of the mass shift is that the mass of the $[\mathrm{M}+\mathrm{Na}]^{+}$is $m / z 24$ greater than that of the corresponding $[\mathrm{M}-\mathrm{H}]^{-}$ion. The corresponding peaks surrounded by boxes in $1 \mathrm{~b}$ are not seen in 1a. The most intense series of peaks in $[\mathrm{M}+\mathrm{Na}]^{+}$spectrum $2 \mathrm{~b}$, labeled as II, has no corresponding series ( $\mathrm{m} / z 24$ less) in the negative ion mode. We assigned these peaks to those molecules 
(a)

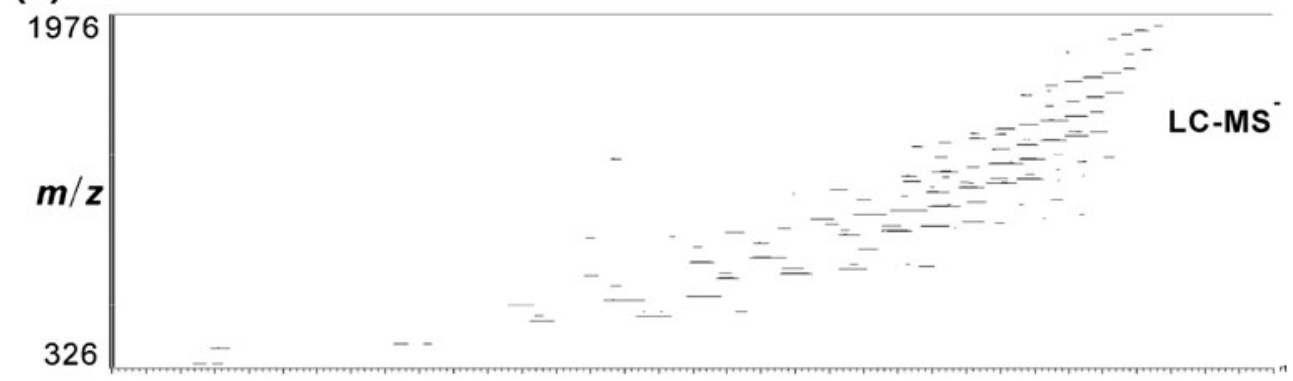

(b)

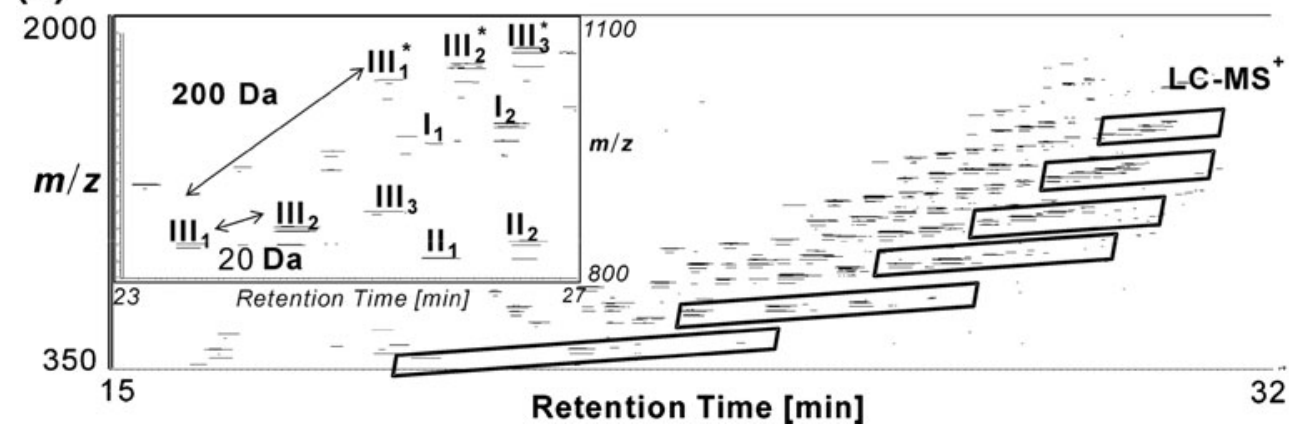

Figure 1. (a) LC-MS data obtained on sample BTA-O showing log abundance of $[\mathrm{M}-\mathrm{H}]^{-}$(line weight) in a coordinate system of $\mathrm{m} / \mathrm{z}$ (as $y$-axis) versus chromatographic elution time (as $x$-axis). (b) The abundance of the BTA molecules with adduct ions in a coordinate system of $\mathrm{m} / \mathrm{z}$ (as $y$-axis) versus chromatographic elution time (as $x$-axis). The insert is the expanded region of (b) with $\mathrm{m} / \mathrm{z}$ 800-1100 ( $y$-axis) and elution time from 23 to $27 \mathrm{~min}(x$-axis)

with cyclic structures. The cyclic polyester structures were not ionized in negative scan mode, due to absence of an acidic (easily abstractable) proton, but with adduct ions in positive mode, they are easily ionized and observed. The mass-tocharge ratios of the cyclic copolyesters and the observation that there were no potential parent ions at the same elution time which would point at fragmentation causing the $\mathrm{m} / \mathrm{z}$ peaks agree well with the structure assignment. This identification of cyclic structures was not achieved by NMR due to overlap with signals from linear structures (see Supplementary Material). As will be shown later in this study, $\mathrm{LC}^{-\mathrm{MS}^{n}}$ results also support this interpretation. Similarly, series IV were assigned to the copolyesters without an acid end group (only have alcohol end groups). They were also observed in positive scan mode but not in negative scan mode, which is dominated by carboxyl end group ions.

The inset in the three-dimensional plot (Figure 1b) clearly demonstrates the presence of a difference of $\mathrm{m} / \mathrm{z} 20$ between eluting oligomers (such as $\mathrm{III}_{1}, \mathrm{III}_{2}$, and $\mathrm{III}_{3}$ ). The mass difference corresponds to the difference between the molecular weight of a butylene adipate (BA, molecular weight: $200 \mathrm{Da}$ ) and a butylene terephthalate (BT, molecular weight: $220 \mathrm{Da}$ ) unit. A homologous series with peak-topeak mass increments of $200 \mathrm{Da}$, such as between $\mathrm{III}_{1}$ and $\mathrm{III}_{1} *$, is also observed. This mass increment exactly equals the mass of the repeating unit of BA. In addition, different combinations of $\mathrm{B}, \mathrm{A}$, and $\mathrm{T}$ result in different compositions. The corresponding mass increments are $72 \mathrm{Da}$ (one extra $\mathrm{B}$ ) and $128 \mathrm{Da}$ (one extra $\mathrm{A}$ ), which are also observed in the spectra. Series III are observed in both negative and positive ion scan spectra with $\mathrm{m} / \mathrm{z} 24$ mass differences (mass differences of the $[\mathrm{M}+\mathrm{Na}]^{+}$and the corresponding $[\mathrm{M}-$ $\mathrm{H}]^{-}$ion). Furthermore, the corresponding positive and negative ions also have the same LC elution time, for example, $\mathrm{III}_{1}$ at $24.4 \mathrm{~min}$. This confirms that the ions with a mass difference of $24 \mathrm{Da}$ in the two scan modes have the same structure.

Using these mass differences the assignments of homologous combinations of the polymer building blocks, 1, 4butanediol (B), terephthalic acid (T), and adipic acid (A) (all three less one $\mathrm{H}_{2} \mathrm{O}$ in their elemental composition) listed in Table 1 could be made in the $m / z$ 663-1009 mass range of the positive ion spectra. These results indicate that the polymers present in the original sample can both be linear and cyclic. The cyclic molecules detected all contain a number of $B$ monomers that equals the sum of the number of $\mathrm{T}$ and $\mathrm{A}$ monomers, which is in line with the structural requirements of cyclic co-polyesters. The linear molecules all have net water $\left(\mathrm{H}_{2} \mathrm{O}\right)$ end groups but in three different ways, viz. (1) with an alcohol end group at both ends, (2) one alcohol end group and one acid end group, and (3) an acid end group at both ends.

LC-MS ${ }^{n}$ spectra of the cyclic structures are very different to those of the linear structures. Figure 3(a) shows the $\mathrm{MS}^{2}$ and $\mathrm{MS}^{3}$ spectra of the cyclic structure $\left[(\mathrm{AB})_{3}+\mathrm{Na}\right]^{+}$ (elemental composition $\left[\mathrm{C}_{30} \mathrm{H}_{48} \mathrm{O}_{12} \mathrm{Na}\right]^{+}$) detected at $\mathrm{m} / \mathrm{z}$ 623. The first neutral loss $(\mathrm{m} / \mathrm{z} 54)$ is only observed in the $\mathrm{MS}^{2}$ spectra of cyclic but not in the tandem mass spectra of 

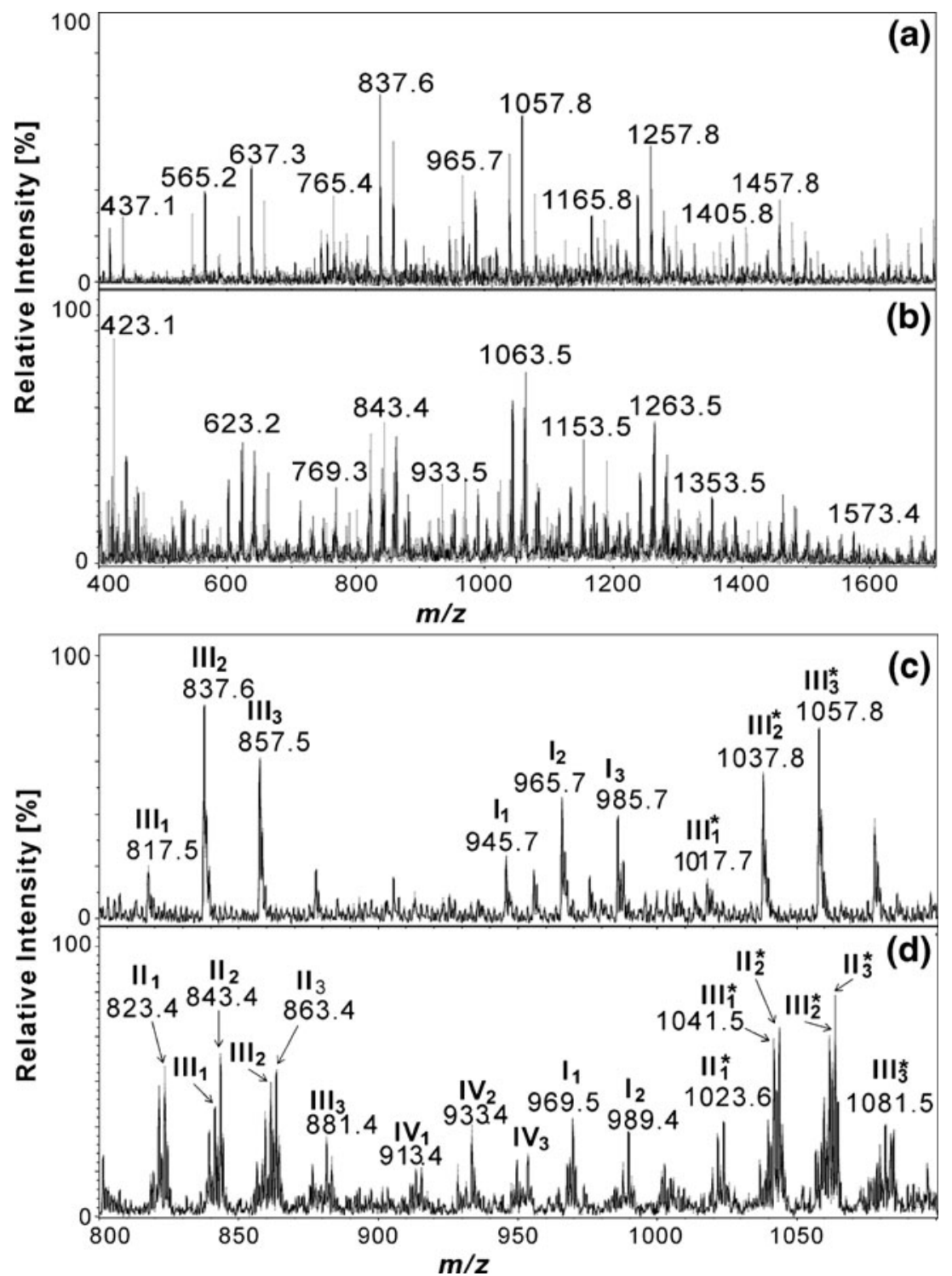

Figure 2. Summation (15'-32') LC-MS spectra of BTA-O: (a), (b) the corresponding spectra to Figure 1a (negative ion mode) and $1 \mathrm{~b}$ (positive ion mode), respectively, and (c) the expanded $(\mathrm{m} / \mathrm{z} 800-1100)$ representation of $(\mathbf{a})$ and $(\mathbf{d})$ the expanded $(\mathrm{m} / \mathrm{z}$ 800-1100) representation of (b)

Table 1. Monomer composition assignments of the spectrum in Figure 2d. See Supplementary Material for schematic of selected structures

\begin{tabular}{|c|c|c|c|c|}
\hline Mass $(m / z)$ & Structure assignments $\left(-\mathrm{Na}^{+}\right)$ & Mass $(m / z)$ & Structure assignments $\left(-\mathrm{Na}^{+}\right)$ & Label in Figure $2 d$ \\
\hline 641 & $\mathrm{H}(\mathrm{AB})_{3} \mathrm{OH}$ & 841 & $\mathrm{H}(\mathrm{AB})_{4} \mathrm{OH}$ & $\mathrm{III}_{1}$ \\
\hline 661 & $\mathrm{H}(\mathrm{AB})_{2}(\mathrm{~TB}) \mathrm{OH}$ & 861 & $\mathrm{H}(\mathrm{AB})_{3}(\mathrm{~TB}) \mathrm{OH}$ & $\mathrm{III}_{2}$ \\
\hline 681 & $\mathrm{H}(\mathrm{AB})(\mathrm{TB})_{2} \mathrm{OH}$ & 881 & $\mathrm{H}(\mathrm{AB})_{2}(\mathrm{~TB})_{2} \mathrm{OH}$ & $\mathrm{III}_{3}$ \\
\hline 713 & $\mathrm{HB}(\mathrm{AB})_{3} \mathrm{OH}$ & 913 & $\mathrm{HB}(\mathrm{AB})_{4} \mathrm{OH}$ & $\mathrm{IV}_{1}$ \\
\hline 733 & $\mathrm{HB}(\mathrm{AB})_{2}(\mathrm{~TB}) \mathrm{OH}$ & 933 & $\mathrm{HB}(\mathrm{AB})_{3}(\mathrm{~TB}) \mathrm{OH}$ & $\mathrm{IV}_{2}$ \\
\hline 753 & $\mathrm{HB}(\mathrm{AB})(\mathrm{TB})_{2} \mathrm{OH}$ & 953 & $\mathrm{HB}(\mathrm{AB})_{2}(\mathrm{~TB})_{2} \mathrm{OH}$ & $\mathrm{IV}_{3}$ \\
\hline 769 & $\mathrm{H}(\mathrm{AB})_{3} \mathrm{AOH}$ & 969 & $\mathrm{H}(\mathrm{AB})_{4} \mathrm{AOH}$ & $\mathrm{I}_{1}$ \\
\hline 789 & $\mathrm{H}(\mathrm{AB})_{3} \mathrm{TOH}$ & 989 & $\mathrm{H}(\mathrm{AB})_{4} \mathrm{TOH}$ & $\mathrm{I}_{2}$ \\
\hline 809 & $\mathrm{H}(\mathrm{AB})_{2}(\mathrm{~TB}) \mathrm{TOH}$ & 1009 & $\mathrm{H}(\mathrm{AB})_{3}(\mathrm{~TB}) \mathrm{TOH}$ & \\
\hline 623 & Cyclic $(\mathrm{AB})_{3}$ & 823 & Cyclic $(\mathrm{AB})_{4}$ & $\mathrm{II}_{1}$ \\
\hline 643 & Cyclic $(\mathrm{AB})_{2}(\mathrm{~TB})$ & 843 & Cyclic $(\mathrm{AB})_{3}(\mathrm{~TB})$ & $\mathrm{II}_{2}$ \\
\hline 663 & Cyclic $(\mathrm{AB})(\mathrm{TB})_{2}$ & 863 & Cyclic $(\mathrm{AB})_{2}(\mathrm{~TB})_{2}$ & $\mathrm{II}_{3}$ \\
\hline
\end{tabular}


(a)

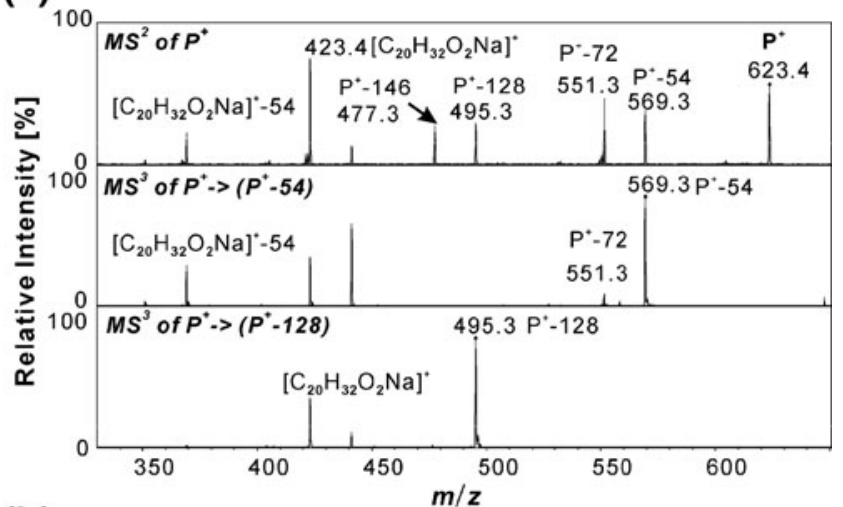

(b)

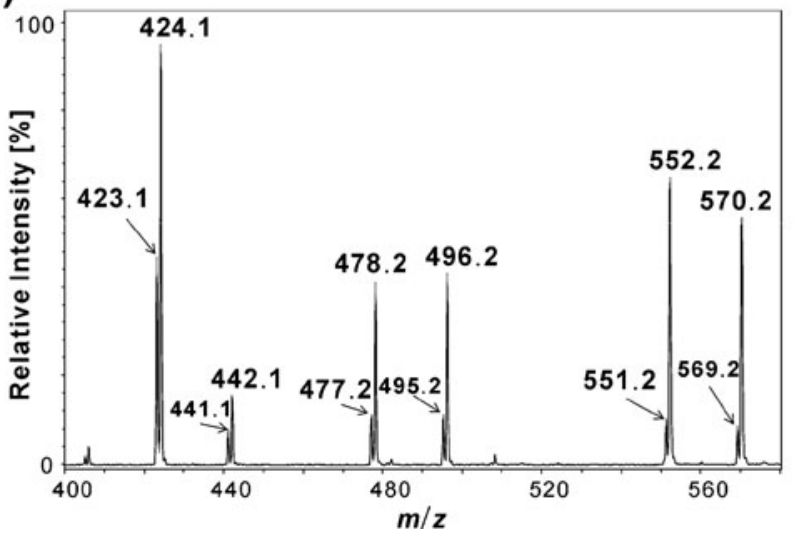

Figure 3. (a) The $\mathrm{MS}^{2}$ of the cyclic structure $\left[(\mathrm{AB})_{3}+\mathrm{Na}\right]^{+}(\mathrm{m} /$ $z$ 623, $\left[\mathrm{C}_{30} \mathrm{H}_{48} \mathrm{O}_{12} \mathrm{Na}\right]^{+}, \mathrm{P}^{+}$) in BTA-O (top panel), $\mathrm{MS}^{3}$ spectra of $\left(\mathrm{P}^{+}-54\right)$ and $\left(\mathrm{P}^{+}-128\right)$ (middle and bottom panel). (b) The $\mathrm{MS}^{2}$ spectrum of first ${ }^{13} \mathrm{C}$ isotope peak $\mathrm{m} / \mathrm{z} 624$ (precursor peak not shown) in BTA-O

the linear structures. Peaks $m / z 495.3$ and 477.3 are observed in the $\mathrm{MS}^{2}$ spectra of $m / z 623.4$ but not in the $\mathrm{MS}^{3}$ spectra of $\mathrm{m} / \mathrm{z}$ 569. Therefore, the formation of these two peaks is attributed to direct neutral losses of 128 and 146, respectively. The other peaks in the $\mathrm{MS}^{2}$ spectrum can all be attributed to neutral losses amounting to combinations of 54, 72,128 , and 146 .

The possible elemental composition of the first neutral loss $(m / z 54)$ could be $\mathrm{C}_{3} \mathrm{H}_{2} \mathrm{O}$ or $\mathrm{C}_{4} \mathrm{H}_{6}$ (based on the raw materials used in the reaction and the isotope pattern of the parent ion suggesting that it only contains $\mathrm{C}, \mathrm{H}$, and $\mathrm{O}$ ). An alternative approach, using $\mathrm{MS}^{2}$ on the first ${ }^{13} \mathrm{C}$ isotope peak, was developed to identify the elemental composition of the neutral loss so that high accuracy $\mathrm{MS}^{2}$ analysis is not needed. $m / z 624$, the first ${ }^{13} \mathrm{C}$ isotope peak of $m / z 623$, contains one ${ }^{13} \mathrm{C}$ and $29{ }^{12} \mathrm{C}$. Theoretically, $\mathrm{MS}^{2}$ on $\mathrm{m} / z 624$ will generate two peaks, at $\mathrm{m} / \mathrm{z} 570$ and 569. If the neutral loss contains three carbons, the ratio of the peak intensities of $\mathrm{m} / \mathrm{z} 570$ and 569 should be 27:3, viz. 9. On the other hand, the ratio of the four carbons' case would be $26: 4$, viz. 6.5 .

Table 2 shows the average peak intensity of several peaks in the $\mathrm{MS}^{2}$ spectra of $\mathrm{m} / \mathrm{z}$ 624. The spectrum is shown in Figure $3 b$. The data were generated in three experiments using the same instrumental setting. Relatively long acquisition times were used to minimize the experimental errors. The fragmentation amplitude used was $0.35 \mathrm{~V}$ to achieve 50\% surviving yield [16] of the precursor ion at $m / z 624$.

As shown in Table 2, the peak intensity ratio of $\mathrm{m} / z 570$ and 569 is 6.4 . The standard deviation of the intensity ratio is 0.03 . Therefore, the $\mathrm{m} / \mathrm{z} 54$ loss contains four carbons and the elemental composition is assigned as $\mathrm{C}_{4} \mathrm{H}_{6}$. Likewise, the elemental composition of the loss of 72 was assigned to $\mathrm{C}_{4} \mathrm{H}_{8} \mathrm{O}$ (B-residue), and the aforementioned attributions of neutral losses 128 (A-residue, adipic anhydride, $\mathrm{C}_{6} \mathrm{H}_{8} \mathrm{O}_{3}$ ), 146 (adipic acid, $\left.\mathrm{C}_{6} \mathrm{H}_{10} \mathrm{O}_{4}\right), 182\left(128\right.$ A-residue, $\mathrm{C}_{6} \mathrm{H}_{8} \mathrm{O}_{3}+$ 54 B-residue, $\left.\mathrm{C}_{4} \mathrm{H}_{6}\right)$, and $200\left(\mathrm{AB}, \mathrm{C}_{10} \mathrm{H}_{16} \mathrm{O}_{4}\right)$ were confirmed. The calculated ratios are all lower than the theoretical values. The underestimation of the first fragment peak resulting from the peak integration algorithm used could be the cause.

All the elemental compositions of the fragments in the following spectra were determined using the same method $\left(\mathrm{MS}^{2}\right.$ on the first ${ }^{13} \mathrm{C}$ isotope peak of the parent ion followed by comparison of the intensity ratio of the fragment peak pairs with the theoretical isotope ratios of proposed elemental compositions) as described above.

In the $\mathrm{MS}^{2}$ spectra of the linear structure $\left[\mathrm{HB}(\mathrm{AB})_{4} \mathrm{OH}+\right.$ $\mathrm{Na}]^{+}$at $m / z$ 913, Figure 4, there is no $m / z 54$ loss $\left(\mathrm{C}_{4} \mathrm{H}_{6}\right)$ as observed in the spectra of cyclic structures. Basically, three kinds of losses are observed. The loss of $m / z 72\left(\mathrm{C}_{4} \mathrm{H}_{8} \mathrm{O}\right)$ is from monomeric unit $\mathrm{B}, \mathrm{m} / z 128\left(\mathrm{C}_{6} \mathrm{H}_{8} \mathrm{O}_{3}\right)$ and $\mathrm{m} / \mathrm{z} 146$ $\left(\mathrm{C}_{6} \mathrm{H}_{10} \mathrm{O}_{4}\right)$ are from monomeric unit $\mathrm{A}$, and $\mathrm{m} / \mathrm{z} 166$ $\left(\mathrm{C}_{8} \mathrm{H}_{6} \mathrm{O}_{4}\right)$ is from monomeric unit $T$. All the fragments mentioned above can be explained by ester bond cleavages of the precursor ions. The consecutive losses of two $\mathrm{m} / \mathrm{z} 72$ $\left(\mathrm{C}_{4} \mathrm{H}_{8} \mathrm{O}\right)$ from $\mathrm{m} / z 913$ indicate $\mathrm{B}$ residues are present at both ends of the chain.

By studying the different fragmentation patterns of the structural isomers, the sequence of the monomeric units in certain structures could be revealed. For example, $\left[\mathrm{H}(\mathrm{AB})_{2}(\mathrm{~TB}) \mathrm{OH}+\mathrm{Na}\right]^{+}(\mathrm{m} / z$ 661) has three different structural (monomer sequence) isomers, shown in Scheme 1.

Figure $5 \mathrm{a}$ is the extracted ion chromatogram of $\mathrm{m} / \mathrm{z} 661$ in an LC-MS ${ }^{2}$ experiment. Two peaks in the chromatogram indicate that at least two different structural isomers are present. Figure $5 \mathrm{~b}$ shows the $\mathrm{MS}^{2}$ spectra of $\mathrm{m} / z 661$ at the two retention times corresponding to the two peaks in the chromatogram. Clearly, the two spectra are different, indicating different fragmentation pathways and structures. A neutral loss of $72\left(\mathrm{C}_{4} \mathrm{H}_{8} \mathrm{O}\right)$ observed in both spectra confirms that a $\mathrm{B}$ residue is present at the end of the chain. This is in line with the monomer composition (i.e., the number of $\mathrm{B}$ residues being equal to the sum of the $\mathrm{T}$ and $\mathrm{A}$ residues). However, in the mass spectrum of the first chromatographic peak a neutral loss of $128\left(\mathrm{C}_{6} \mathrm{H}_{8} \mathrm{O}_{3}\right)$ corresponding with the mass of an $\mathrm{A}$ residue (adipic 
Table 2. Intensities and ratios of the peaks generated in the $\mathrm{MS}^{2}$ of first ${ }^{13} \mathrm{C}$ isotope peak $m / z$ in the mass spectrum of BTA-O

\begin{tabular}{|c|c|c|c|c|c|c|c|}
\hline & $m / z$ : & Theoretical & Exp. 1 & Exp. 2 & Exp. 3 & Average & Standard Deviation \\
\hline Frag 1 & 570 & 26 & 2515 & 2812 & 2798 & & \\
\hline Frag 1* & 569 & 4 & 396 & 435 & 439 & & \\
\hline ratio $1: 1^{*}$ & & 6.50 & 6.35 & 6.46 & 6.37 & 6.40 & 0.03 \\
\hline Frag 2 & 552 & 26 & 2896 & 3220 & 3245 & & \\
\hline Frag $2 *$ & 551 & 4 & 474 & 518 & 516 & & \\
\hline ratio $2: 2 *$ & & 6.50 & 6.11 & 6.22 & 6.29 & 6.20 & 0.04 \\
\hline Frag 3 & 496 & 24 & 2041 & 2147 & 2165 & & \\
\hline Frag $3 *$ & 495 & 6 & 523 & 559 & 562 & & \\
\hline ratio $3: 3^{*}$ & & 4.00 & 3.90 & 3.84 & 3.85 & 3.87 & $0.00(1)$ \\
\hline Frag 4 & 478 & 24 & 1908 & 2070 & 2054 & & \\
\hline Frag 4* & 477 & 6 & 488 & 567 & 562 & & \\
\hline ratio $4: 4^{*}$ & & 4.00 & 3.91 & 3.65 & 3.65 & 3.74 & 0.08 \\
\hline Frag 5 & 442 & 20 & 733 & 806 & 787 & & \\
\hline Frag 5* & 441 & 10 & 373 & 407 & 403 & & \\
\hline Ratio 5:5* & & 2.00 & 1.97 & 1.98 & 1.96 & 1.97 & 0.02 \\
\hline Frag 6 & 424 & 20 & 4286 & 4774 & 4747 & & \\
\hline Frag 6* & 423 & 10 & 2290 & 2362 & 2351 & & \\
\hline Ratio $6: 6^{*}$ & & 2.00 & 1.87 & 2.02 & 2.02 & 1.97 & 0.09 \\
\hline
\end{tabular}

Frag $\mathrm{x}$ contain one ${ }^{13} \mathrm{C}$

Frag $\mathrm{x}^{*}$ are the fragments corresponding to Frag $\mathrm{x}$ but contain no ${ }^{13} \mathrm{C}$

anhydride) and a neutral loss of $146\left(\mathrm{C}_{6} \mathrm{H}_{10} \mathrm{O}_{4}\right)$ corresponding with the mass of an adipic acid molecule are observed. These losses are not observed in the tandem mass spectrum of the second chromatographic peak. Therefore monomeric unit A must form an endgroup of the chain of the material eluting in the first chromatographic peak. On the other hand, the occurrence of the loss of $m / z 166\left(\mathrm{C}_{8} \mathrm{H}_{6} \mathrm{O}_{4}\right.$, terephthalic acid) in the tandem mass spectrum of the second chromatographic peak indicates that the substance eluting there has a terephthalic monoester as end group of the structure. A loss of $148 \mathrm{Da}$ is not observed due to steric hindrance in the formation of terephthalic anhydride.

Therefore, the structures in Scheme 1 are assigned to the chromatogram and the spectra as indicated by the labels in Figure 5. The first peak in the EIC and the corresponding spectrum were generated by Structures (1) and (2) and the second peak and its spectrum were from Structure (3).
The LC-MS spectra of BTA-35 and BTA-75 show no difference in either peaks or their intensity. The very early elution time of TBA $\mathrm{OH}$ in the chromatography of the degraded samples avoids interference of the usually dominant TBA OH signal with the mass spectra of the degraded products in LC-MS. The summation ( $5^{\prime}-32^{\prime}$ ') LC-MS spectrum of BTA-75 is shown in Figure 6a. Significant changes are observed in the mass spectrum of BTA-75 compared with the spectrum of BTA-O. The peaks from cyclic structures are not observed in the spectrum anymore; apparently they were converted to linear structures during the hydrolysis/degradation process and went through methanol transesterification to form methyl end groups.

Peaks with different last digits of the $\mathrm{m} / \mathrm{z}$ values are labeled as such, ' 3 ' as series V, ' 5 ' as series VI and '7' as series VII and assigned to three end groups. Series V are those BTA with alcohol end groups at both ends. They were

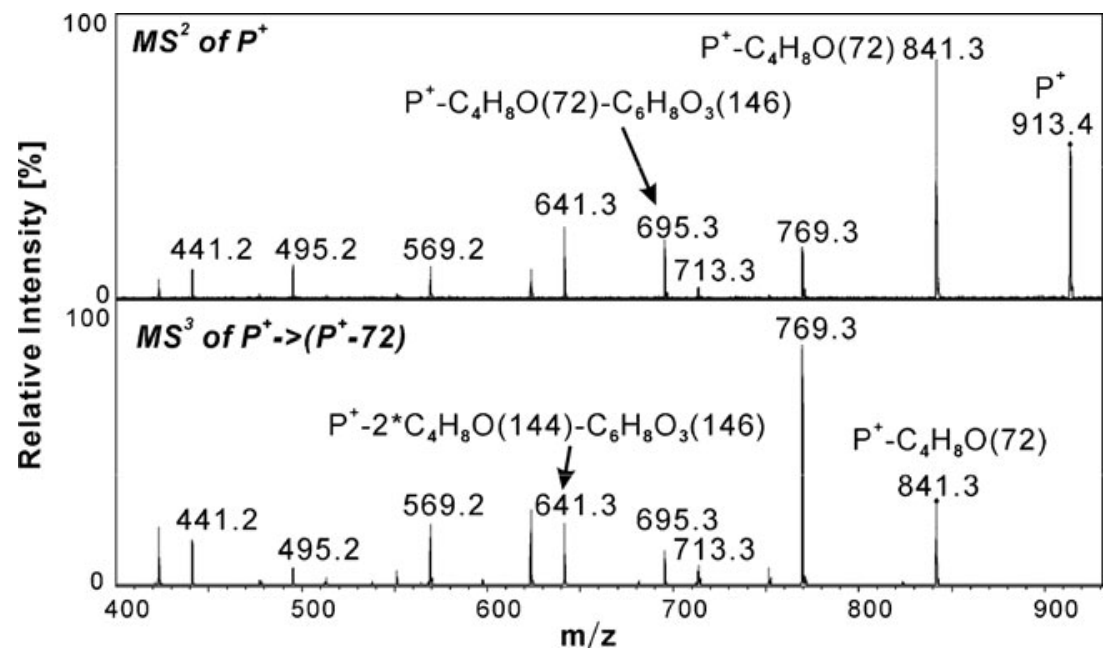

Figure 4. The $\mathrm{MS}^{2}$ of linear structure $\left[\mathrm{HB}(\mathrm{AB})_{4} \mathrm{OH}+\mathrm{Na}\right]^{+}\left(\mathrm{m} / \mathrm{z} 913, \mathrm{P}^{+}\right)$and $\mathrm{MS}^{3}$ spectra of $\left(\mathrm{P}^{+}-72\right)$ in $\mathrm{BTA}-\mathrm{O}$ 
(1)<smiles>CC(C)(C)CCCCOC(=O)CCCC(=O)OCCCCOC(=O)c1ccc(C(=O)OCCCCOC(=O)CCCCC(=O)O)cc1</smiles>

(2)

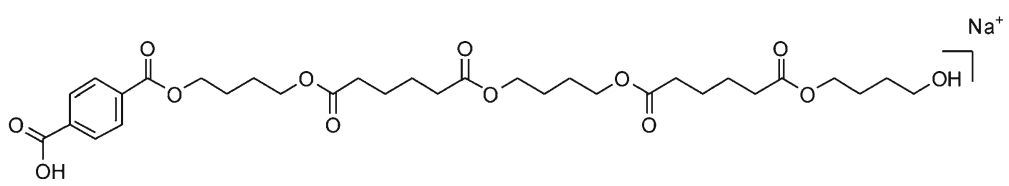

Scheme 1. Possible sequences of $\left[\mathrm{H}(\mathrm{AB})_{2}(\mathrm{~TB}) \mathrm{OH}+\mathrm{Na}\right]^{+}(\mathrm{m} / \mathrm{z} 661$ detected in BTA-O)

not transesterified by methanol in the hydrolysis/degradation process. Therefore the end groups remained the same. The unchanged $\mathrm{MS}^{n}$ spectra of these peaks also confirm this point. Series VI are the BTAs with one alcohol end group at one end and an acid end group at the other. For these molecules the methanol transesterification that took place in the hydrolysis/degradation process resulted in a net change of $\mathrm{m} / \mathrm{z} 14$ in the end group, which is attributed to a methyl end group $\left(\mathrm{CH}_{3}\right)$ instead of hydrogen $(\mathrm{H})$. Series VII are those BTAs with a methyl end group at each end.

Figure $6 \mathrm{~b}$ is the $\mathrm{MS}^{2}$ spectrum of $m / z 797.5$ from series VII. A unique loss of $\mathrm{m} / \mathrm{z} 160$ is observed in peaks from

(a)

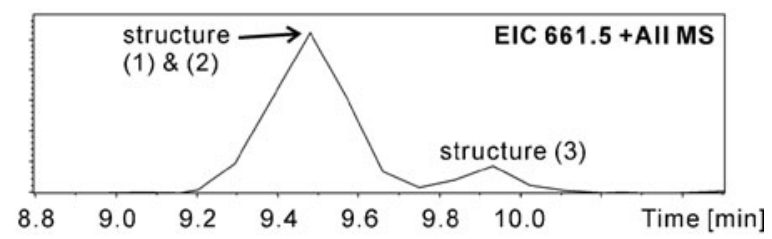

(b)

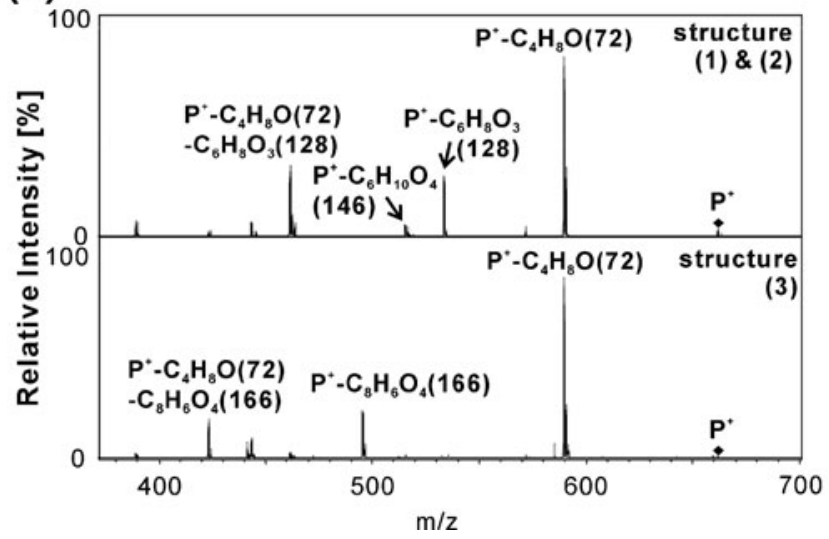

Figure 5. (a) The extracted ion chromatogram of $\left[\mathrm{H}(\mathrm{AB})_{2}(\mathrm{~TB})\right.$ $\mathrm{OH}+\mathrm{Na}]^{+}\left(\mathrm{m} / \mathrm{z} 661, \mathrm{P}^{+}\right)$in LC-MS ${ }^{2}$ of BTA-O. (b) The $\mathrm{MS}^{2}$ spectra of $\mathrm{P}^{+}$at the retention times corresponding to the two peaks in the extracted ion chromatogram series VII that is not observed in the other series. Two consecutive losses of $\mathrm{m} / \mathrm{z} 160$ from 797.5 to 637.3 and then to 477.2 are observed in the spectrum, which indicates the loss of the same end groups on both sides of the structure. $\mathrm{MS}^{2}$ on the first ${ }^{13} \mathrm{C}$ isotope peak of the parent ion indicated that the elemental composition of the $m / z 160$ is $\mathrm{C}_{7} \mathrm{H}_{12} \mathrm{O}_{4}$,
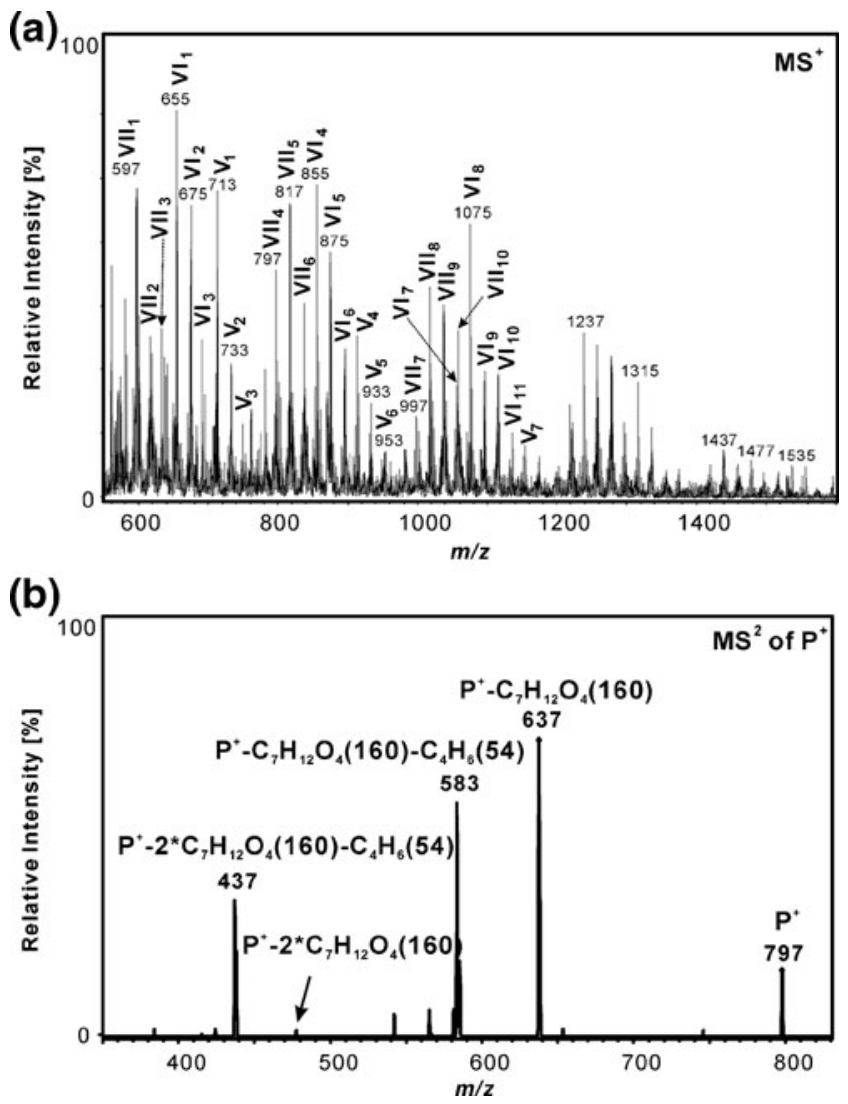

Figure 6. (a) The summation $\left(5^{\prime}-32^{\prime}\right)$ LC-MS spectrum of BTA-75. (b) The $\mathrm{MS}^{2}$ spectra of $\left[\mathrm{CH}_{3} \mathrm{~A}(\mathrm{BA})_{3} \mathrm{OCH}_{3}+\mathrm{Na}\right]^{+}(\mathrm{m} / \mathrm{z}$ $797.5, \mathrm{P}^{+}$) from series VII detected in sample BTA-75 
and indicates the presence of adipic acid methyl ester end groups.

\section{Conclusions}

The results of the present study reveal that the molecular structure of BTA copolyester and its partially degraded products can be determined by the LC-MS ${ }^{n}$ analysis.

The method allows detailed identification of endgroup structures in both the original and the partially degraded material. Comparison of LC-MS data obtained in positive and negative mode allows the identification of cyclic structures, which are not clearly identified using NMR.

Comparison of LC-MS data of degraded and original material shows that the cyclic structures are no longer present in the degraded material. The occurrence of transesterification by methanol during the degradation process was confirmed by the identification of methyl endgroups in degraded samples. Furthermore, the comparative LC-MS analysis of the two partially degraded samples (at $35^{\circ} \mathrm{C}$ and $75^{\circ} \mathrm{C}$ ) showed that the temperature influences the extent but not the nature of the degradation reaction.

$\mathrm{MS}^{2}$ experiments on the first ${ }^{13} \mathrm{C}$ isotope peak helps to confirm the elemental composition of the fragments. It may be used to provide an alternative for high mass accuracy $\mathrm{MS}^{2}$ experiments, when such an instrument is not available in the lab.

\section{Acknowledgments}

The authors acknowledge that this work is part of the POLYMS project on multistage mass spectrometry of synthetic polymers and synthetically modified biopolymers (MEST-CT2005-021029) and funded by the European Commission in the framework of the Marie Curie Early Stage Training Program. The research project was also partially supported by European Union European Regional Development Fund, contract no. POIG.01.03.01-00-018/08-00. J.S. acknowledges AkzoNobel for financial support. The authors acknowledge Professor Ron Heeren, Dr. Tony Jackson, Andreas Nasioudis, and Jan van Velde for useful discussions.

\section{References}

1. Lee, S.-R., Park, H.-M., Lim, H., Kang, T., Li, X., Cho, W.-J., Ha, C.S.: Microstructure, tensile properties, and biodegradability of aliphatic polyester/clay nanocomposites. Polymer 43, 2495-2500 (2002)

2. Witt, U., Müller, R.J., Deckwer, W.D.: Studies on sequence distribution of aliphatic/aromatic copolyesters by high-resolution ${ }^{13} \mathrm{C}$ nuclear magnetic resonance spectroscopy for evaluation of biodegradability. Macromol. Chem. Phys. 197, 1525-1535 (1996)

3. Witt, U., Müller, R.J., Deckwer, W.D.: Biodegradation behavior and material properties of aliphatic/aromatic polyesters of commercial importance. J. Polym. Environ. 5, 81-89 (1997)

4. Marten, E., Müller, R.J., Deckwer, W.D.: Studies on the enzymatic hydrolysis of polyesters. II. Aliphatic-aromatic copolyesters. Polym. Degrad. Stab. 88, 371-381 (2005)

5. Dacko, P., Kowalczuk, M., Janeczek, H., Sobota, M.: Physical properties of the biodegradable polymer compositions containing natural polyesters and their synthetic analogues. Macromol. Symp. 239, 209216 (2006)

6. Adamus, G., Sikorska, W., Kowalczuk, M., Montaudo, M., Scandola, M.: Sequence distribution and fragmentation studies of bacterial copolyester macromolecules: Characterization of PHBV macroinitiator by electrospray ion-trap multistage mass spectrometry. Macromolecules 33, 5797-5802 (2000)

7. Witt, U., Yamamoto, M., Seeliger, U., Müller, R.-J., Warzelhan, V.: Biodegradable polymeric materials - not the origin but the chemical structure determines biodegradability. Angew. Chem. Int. Ed. 38, 14381442 (1999)

8. Rychter, P., Kawalec, M., Sobota, M., Kurcok, P., Kowalczuk, M.: Study of aliphatic-aromatic copolyester degradation in sandy soil and its ecotoxicological impact. Biomacromolecules 11, 839-847 (2010)

9. Gan, Z., Kuwabara, K., Yamamoto, M., Abe, H., Doi, Y.: Solid-state structures and thermal properties of aliphatic-aromatic poly(Butylene Adipate-co-Butylene Terephthalate) copolyesters. Polym. Degrad. Stab. 83, 289-300 (2004)

10. Witt, U., Einig, T., Yamamoto, M., Kleeberg, I., Deckwer, W.D., Müller, R.J.: Biodegradation of aliphatic-aromatic copolyesters: Evaluation of the final biodegradability and ecotoxicological impact of degradation intermediates. Chemosphere 44, 289-299 (2001)

11. Adamus, G.: Molecular level structure of (R, S)-3-Hydroxybutyrate/(R, S)-3-Hydroxy-4-ethoxybutyrate copolyesters with dissimilar architecture. Macromolecules 42, 4547-4557 (2009)

12. Arnould, M.A., Wesdemiotis, C., Geiger, R.J., Park, M.E., Buehner, R. W., Vanderorst, D.: Structural characterization of polyester copolymers by MALDI mass spectrometry. Prog. Org. Coat. 45, 305-312 (2002)

13. Wesdemiotis, C., Solak, N., Polce, M.J., Dabney, D.E., Chaicharoen, K., Katzenmeyer, B.C.: Fragmentation pathways of polymer ions. Mass Spectrom. Rev. 10.1002/mas.20282.

14. Nielen, M.W.F., Buijtenhuijs, F.A.: Polymer analysis by liquid chromatography/electrospray ionization time-of-flight mass spectrometry. Anal. Chem. 71, 1809-1814 (1999)

15. Murgasova, R., Hercules, D.: Polymer characterization by combining liquid chromatography with MALDI and ESI mass spectrometry. Anal. Bioanal. Chem. 373, 481-489 (2002)

16. Heeren, R.M.A., Vékey, K.: A novel method to determine collisional energy transfer efficiency by fourier transform ion cyclotron rresonance mass spectrometry. Rapid Commun. Mass Spectrom. 12, 1175-1181 (1998) 